\title{
Bridging the Valley of Death: Examining the Work Environment Influencing Adoption of Innovations in Engineering Education
}

\section{Dr. Kirsten A Davis, Boise State University}

Dr. Kirsten A. Davis is an assistant professor in the Construction Management Department within the College of Engineering at Boise State University. Dr. Davis earned a B.Arch. in Architecture and a B.S. in Civil Engineering from the University of Tennessee, an M.S. in Civil Engineering specializing in Construction Engineering and Management from the University of Colorado, Boulder, and a Ph.D. in Civil Engineering specializing in Construction Engineering and Management from Virginia Polytechnic Institute and State University. Her educational research interests are focused on improving construction management education.

\section{Dr. Ross A. Perkins, Boise State University}

Dr. Perkins is an associate professor in the Department of Educational Technology at Boise State University, where he also serves as the coordinator of the department's Ed.D. program. His research interests include the diffusion and adoption of technologies and innovations for education, mobile learning, instructional design for distance education in STEM and other disciplines, and ICT integration in developing nations. He is the Co-PI on two grants funded by the National Science Foundation (engineering ed. and geosciences) and serves as senior personnel (evaluator) for a third NSF-sponsored grant (STEM education). He is active in the Association of Educational Communications and Technology (AECT) and has served as president of its International Division. He is also a member of the American Educational Research Association (AERA). Perkins earned his Ph.D. at Virginia Polytechnic Institute and State University.

\section{Dr. R. Casey Cline, Boise State University}

Dr. Casey Cline is an assistant professor in the Construction Management Department within the College of Engineering at Boise State University. Dr. Cline earned a B.S. in Business Administration from Oklahoma State University, an M.S. in Construction Science from the University of Oklahoma, and a Ph.D. in Education (Adult Development Organizational Learning) from The University of Idaho. His educational research interests are focused on improving construction management processes to facilitate the efficient management of construction projects. His over 25 years of construction industry experience includes work in commercial, industrial, petrochemical, light commercial, and residential construction. He has held positions as project manager, project engineer, superintendent, field engineer, carpenter, and laborer.

\section{Dr. Sondra M Miller, Boise State University}

Dr. Sondra M. Miller is an assistant professor in the Department of Civil Engineering within the College of Engineering at Boise State University. Miller earned a B.S. in Civil Engineering and a M.S. in Environmental Engineering from the State University of New York at Buffalo, and a Ph.D. in Environmental Engineering from the University of Iowa. Her educational research interests are focused on methods to attract and retain women and underrepresented minorities in STEM fields. 


\title{
Bridging the Valley of Death: Examining the Work Environment Influencing Adoption of Innovations in Engineering Education
}

\begin{abstract}
There is a nationwide need to better translate engineering education research into the classroom setting. Moving engineering education research into practice is a more complicated task than it might initially seem. There are many significant barriers to hinder the transition from research to implementation. These barriers can be categorized into two groups: (1) individual barriers, such as personality characteristics that contribute to a lack of willingness to implement innovations, as well as a lack of knowledge about engineering education research; and (2) environmental perceptions, such as perceptions of the tenure and promotion process that suggest a lack of support for innovations.

The project discussed in this paper investigates the characteristics of faculty members who successfully adopt engineering education innovations and studies the impact of their working environment on their decision to adopt. The project also investigates characteristics of faculty members who do not adopt engineering education innovations and whether that decision was affected by perceptions of their working environment.

This paper describes preliminary results of a data collection effort identifying current barriers faculty members have in the adoption of innovations in engineering education. This paper presents data from three perspectives: that of students, administrators, and published documents. These perspectives are part of a larger $360^{\circ}$ approach for data collection that also includes the perspectives of self and colleagues. This $360^{\circ}$ approach provides a foundation for bridging the gap, often referred to as the 'valley of death,' between engineering education research and the common practice of engineering education.
\end{abstract}

\section{Introduction}

Translating research into practice is always challenging, regardless of the context. Many innovations never make it to practice and instead disappear into the chasm known as the "valley of death' ${ }^{1}$. Engineering education innovations are not immune to this often-repeating scenario. Research in engineering education is supported through funding from organizations such as the National Science Foundation (NSF) and is published in journals such as the Journal of Engineering Education, yet research results are not often put into practice in engineering classrooms across the United States ${ }^{2}$.

In order to prepare our future engineers with competencies well beyond those expected of past engineers, as the American Society for Engineering Education (ASEE) and the National Academy of Engineering (NAE) say we must, engineering education itself must change and become more effective and efficient ${ }^{3,4}$. We must draw on available engineering education research to improve our classrooms and our teaching both now and into the future. 
This is not a simple task, as there are many barriers to overcome. Some are barriers of individual faculty members, and others reflect their work environment. Some examples of these barriers are listed below.

- Individual barriers:

- Personality characteristics contribute to an individual faculty member's desire and willingness to implement or ignore innovations in engineering education ${ }^{5,6}$.

$\circ$ Current and emerging faculty members are highly skilled in the technical aspects of their engineering specialty while pedagogy is often missing from their professional development ${ }^{5,7}$.

○ Many faculty members lack specific knowledge of current research in engineering education $^{4,5}$.

- Environmental Perceptions:

- Perceptions of the tenure and promotion system at many institutions suggest that changes in engineering education are not supported ${ }^{4,5,8}$.

- Faculty members perceive that rewards and incentives for implementing innovations in engineering education are not rewarded at the same level as advances in scholarly pursuits ${ }^{9,10}$.

- Demands of faculty members to teach courses, conduct scholarly activity, and perform service contribute to a perceived lack of time to implement innovations in engineering education ${ }^{9,11}$.

To address these challenges, this research project investigates the characteristics of faculty members who successfully adopt engineering education innovations and studies the impact of their working environment on their decision to adopt. Additionally, the project investigates characteristics of faculty members who do not adopt engineering education innovations and whether that decision was affected by perceptions of their working environment. This work promotes successful faculty characteristics and work environments by recognizing aspects that are effective in the transition from research to practice. It also acknowledges faculty characteristics and perceptions of work environments that may impede the successful adoption of engineering education innovations into the classroom. This project promotes a realignment of individual and institutional priorities through the development of an implementation model aimed at increasing the number of faculty successfully adopting education innovations. A detailed overview of the project and its plan of work is discussed elsewhere ${ }^{12}$.

\section{0-Degree Data Collection}

The data on this project was collected using a 360-degree or multi-rater type of collection method. The 360-degree method is commonly used in performance evaluations, providing feedback to an individual from multiple perspectives ${ }^{13}$. This method provides data for this project from many different perspectives forming a reliable and valid picture of faculty member characteristics and their work environment perceptions. Perspectives include that of self, colleagues, students, experts in education innovation (such as the director of a center for teaching and learning), and the reality (from administrators and published documents) and perceptions (from individuals) of the tenure process and rewards/incentives (see Figure 1). 


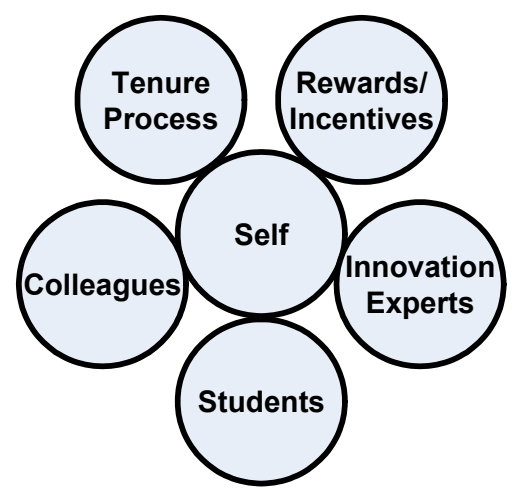

Figure 1. 360-degree data collection

The sample for this project was faculty in the College of Engineering (COEN) at Boise State University (BSU), a predominantly undergraduate university. There are approximately 70 tenured and tenure-track faculty members in COEN serving approximately 1,500 undergraduate and 300 graduate students.

Data was collected from self-report surveys of faculty and characterizes individual faculty members ('self' in Figure 1) willingness to use a new innovation, their knowledge about engineering education innovations, as well as their perceptions on the tenure process and the reward/incentive structure of their work environment. Self-report surveys were also used to gather opinions/ratings from faculty regarding whether their colleagues use engineering education innovations in the classroom. The data from these collection efforts was discussed previously $^{14}$.

This paper discusses three additional data sources and their preliminary findings:

- Self-report surveys collected from students enrolled in courses taught by faculty members who use (or claim to use) engineering education innovations in their classroom to provide an additional perspective on the reliability and validity of the self-report data from faculty;

- Document analysis that examined the published information regarding the tenure process and the reward/incentive structure at the University; and.

- Individual structured interviews conducted with the Dean and Associate Dean of Engineering, as well as the Provost, to learn how the tenure process and the reward/incentive structure within the College of Engineering, and at the University overall, are viewed by the administration.

\section{Perspectives of Students}

To provide an additional perspective on self-report data from faculty regarding their use of engineering education innovations in the classroom, students enrolled in courses within COEN were surveyed electronically. They were asked about instructional methods and technology tools used by faculty teaching engineering classes. The students' responses allowed for confirmation of the reliability and validity of the faculty self-reports.

A brief look at the faculty data is necessary to demonstrate the use of the student data. Faculty answered questions in their self-report survey that provided information about their willingness 
to use a new innovation in their classroom, as well as their knowledge about engineering education innovations. Each of the researchers reviewed and analyzed the faculty data independently to arrive at a particular faculty member's willingness and knowledge level. Both qualitative and quantitative analysis methods were used among the researchers. The levels of willingness and knowledge were plotted by each researcher on a modified Johari Window ${ }^{15}$ representing the faculty member's probable stage of adoption of engineering education innovations (see Figure 2). The centroid and range of the researchers' individual results were also plotted (see Figure 3). While there is some variation in individual researcher results, it is highly likely that the actual stage of adoption of the faculty member falls within the range identified. The variation also reflects the fact that determining a faculty member's knowledge about engineering education innovations and their willingness to use them is highly subjective and very difficult to evaluate accurately.

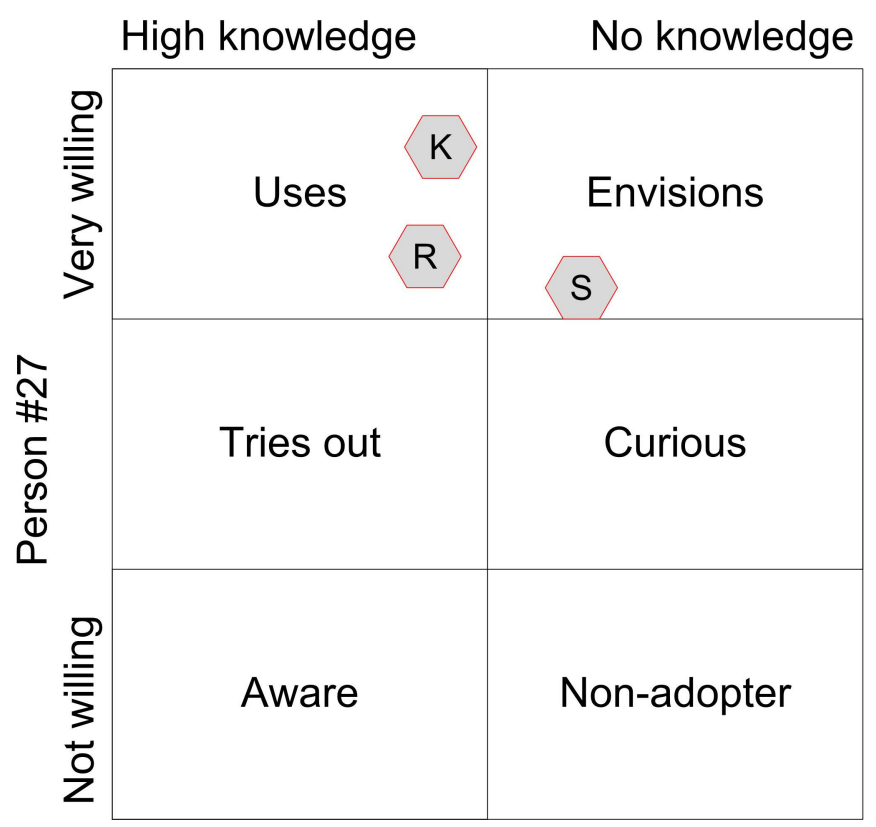

Figure 2. Modified Johari Window showing individual researcher results 


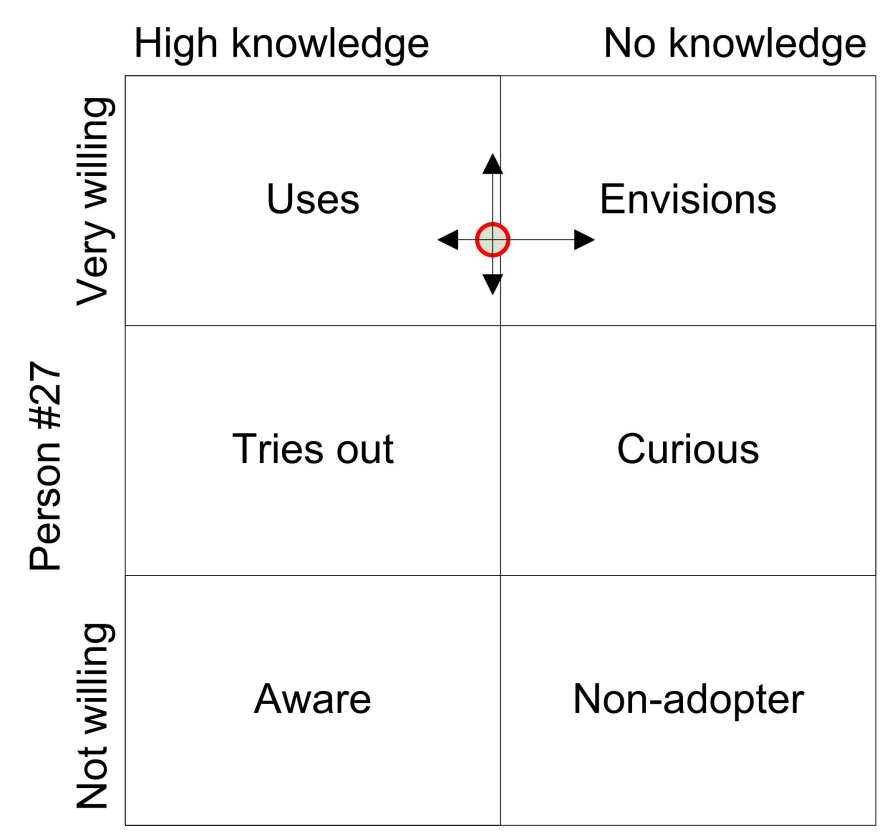

Figure 3. Modified Johari Window showing centroid and range of individual researcher results

The student data was collected for approximately one-third of the faculty that completed the selfreport surveys and was used for validity and reliability purposes. Because it is extremely difficult for a student to recognize how much knowledge a faculty member might have about engineering education innovations, this was not measured. Instead, student data was used to confirm or deny the apparent willingness of faculty to use innovations in their classrooms.

Students reported on what was happening in their classes in terms of instructional methods and technology tools. Students were asked if a particular method or tool was used in a specific course they were taking or had just completed. Examples of instructional methods include lecture, case study presentations, collaboration with classmates, experimentation or discovery, and hands-on experiences. Examples of technology tools include Blackboard (online learning) content, graphing calculators, mobile tools (iPads, phones, etc.), use of specific software while in class, and web-based experiments, simulations, or demonstrations.

In all but one case, the student reports reflected each faculty member's probable level of willingness to use engineering education innovations in their classroom, confirming the data collected by the faculty in self-reports. In the single odd case, which needs to be analyzed further, the students rated the probable level of willingness much higher than the faculty member's self-report reflects.

\section{Perspectives of Policy Documents}

A document analysis was performed to examine the published information regarding the tenure process and the reward/incentive structure at the University. These documents represent a portion of the work environment that must be evaluated in order to provide the 360-degree view desired. It is expected that the data gathered from the published documents will differ from the 
perceptions of individual faculty members, as well as differ from the information received in the interviews from administrators, once a detailed analysis is performed.

University and engineering college policies and procedures are established to provide criteria to be used as a guide for the equitable and consistent management of university personnel and to ensure that the university mission to educate people and foster an intellectual atmosphere is achieved. A comprehensive review of the policies and procedures detail numerous rules for faculty workload, faculty evaluation, and faculty tenure and promotion, but these policies and procedures vary greatly in their recognition or support for the use of new teaching innovations.

University-wide workload policies and procedures are used to establish the assignment of workload for tenured and tenure-track faculty. The intent is to provide criteria for the balance of scholarly and service interests of faculty members with the responsibility of delivering academic programs of high quality ${ }^{16}$. A review of the criteria does not establish specific workload policies related to new teaching innovations, but options are available to adjust workload for factors that significantly impact effort, including service learning and/or hybrid courses.

Policies and procedures for the evaluation of faculty members include the establishment of criteria for student, peer, and institution evaluations. Student evaluations are designed to assess the faculty member's teaching ability and effectiveness ${ }^{17}$. While teaching ability and effectiveness are mentioned, there is no specific reference to new teaching innovations. Institutional and peer evaluation policies and procedures do make reference to the recognition of new teaching innovations, stating that evidence of efforts to improve teaching such as incorporation of field projects into a course, adoption of a new teaching method, or an innovational instructional use of media must be documented ${ }^{18}$. These policies and procedures also state that the evaluation process should encourage faculty to enhance their abilities in areas of personal interest and pursue new directions of study to improve their performance ${ }^{19}$.

Promotion and tenure policies and procedures are established as guidelines for faculty promotion. These policies state that candidates for promotion will be advanced for promotion only when records clearly demonstrate outstanding performance, and commitment to teaching. Further, effective and outstanding teaching are recognized as essential for promotion, and this includes the recognition of efforts to use innovations in teaching design, learning activities, and the use of new and emerging technologies ${ }^{20,21}$.

A comprehensive review of university and engineering college policies and procedures reveal that innovations in teaching and the use of new teaching applications are valued for candidates for tenure and promotion. However, faculty workload and evaluation policies and procedures do not specifically mention the use of innovations or new teaching applications. One reason for these inconsistencies may be that the current versions of these policies are significantly older than the tenure and promotion policies.

\section{Perspectives of Administrators}

For the final piece of the 360-degree evaluation, researchers sought perspectives of administrators in the College of Engineering (COEN) and in the upper administration of the 
university about the possible impact of promotion and tenure (P\&T) policies on tenure-track professors' willingness to adopt teaching innovations in their engineering courses. The rationale for this aspect of the study stems in part from previous papers that emphasize the role that P\&T plays in the culture of adoption in academics ${ }^{22-25}$. Some have suggested that tenure, in its traditional conceptualization, creates a barrier to innovativeness rather than cultivate $\mathrm{it}^{26}$. It is therefore necessary to examine not only how faculty perceive P\&T policy, but to examine how administrators interpret it as well.

A member of the research team interviewed each of the administrators using a semi-structured questionnaire developed by the research team. The interviews, lasting approximately 45 minutes, were digitally recorded and then transcribed so that the comments could be analyzed. The interviews included questions related to the participants' definition of teaching effectiveness and innovation, the impact of student evaluations on the P\&T process, how innovations might be communicated to faculty members, and so forth (see the appendix for list of questions).

A faculty member seeking promotion and/or tenure at Boise State University must adhere to two sets of complementary guidelines. In the first instance, she or he must follow a college-level process that ends when the dean of the given college makes a decision based on the input of a college-level committee. Following the dean's recommendation, a subset of the applicant's materials are sent for final approval by the provost, the institution's highest academic officer. COEN has two documents pertaining to the P\&T process ${ }^{19,21}$, and the university has two that address tenure and promotion separately ${ }^{20,27}$. A number of other university policy documents address elements related to $\mathrm{P} \& \mathrm{~T}$, such as those that describe student evaluations, annual faculty evaluation policy, etc.

Four themes stand out from the interviews with the participants, all of whom are experienced faculty members, two of whom achieved tenure at Boise State University before eventually moving into administrative position. First, when asked about "teaching effectiveness," a term that appears in the university's P\&T policy documents, it was seen in terms of what students can do with information following a course. All conceded that the only real measure of "effectiveness" would have to be in terms of performance in a subsequent course (though this is not done in a systematic fashion, at least not within COEN). Notably, "effectiveness" was not immediately associated with knowledge of or use of teaching innovations.

When asked about the role of innovations in teaching, the participants were of the same mind. Essentially, an innovation is seen as "trying something new," but this may or may not be "innovative" in the broader view of research in engineering education. Given that students do not always react positively to new (untested) approaches or assignments, and because student evaluations of faculty play such an important role in the P\&T process, administrators were asked what kind of comfort-level a faculty member might have if she or he wanted to pursue "something new" in classes. All agreed that a given set of student evaluations are part of a much larger picture. Promotion and tenure committees and others involved in the faculty evaluation process leading up to P\&T need to look for trends, they insisted, and that all evaluations should be accompanied by faculty reflections of what was attempted and lessons learned. Not discussed was how this insight into evaluations might be communicated to faculty, especially to pre- 
tenured faculty who might be intimidated by the centrality of student evaluations in the P\&T process.

The university policy states that all three aspects of a P\&T dossier must be "effective" or "outstanding." The COEN faculty promotion guidelines, however, state, "it is not anticipated or desired that all faculty will make equal contributions in all three areas and a desirable diversity in contribution is encouraged." The administrators were asked to react to the assertion that the message seems to be that teaching is not necessarily held in high regard, as long as one is doing outstanding work in other areas. The two COEN interviewees, however, saw little discrepancy because they disagreed that the statements were mutually exclusive. One pointed out that "desirable diversity" and "not equal contributions" simply refers to workload and not variations of quality. The other participant, who has never been affiliated with COEN directly, admitted that the language is not as clear as it could be and would benefit from revision.

A third theme arising from the interviews is that all held the position that change (leading to broader adoption of innovative teaching practices) is not something that would come through institutional policies or even further incentive programs. All pointed to the university's Center for Teaching and Learning (CTL) as a place where faculty are encouraged to pursue professional development opportunities, and regular attendance prior to submitting a P\&T application is recognized by the existing policy. Instead, the participants pointed to organic change that happens in one of two ways. The primary mechanism would be for faculty members themselves to try new teaching methods and then share these with colleagues in faculty meetings or other venues. Another mechanism would be for department chairpersons to build into conversations during the annual review for each faculty member (pre-tenured or tenured) questions that essentially ask what the person is doing in her or his class that is new or different.

Finally, one of the primary issues identified in the survey of faculty had to do with the parsing of time between research, teaching, and service. The faculty indicated that there is a distinct difference between the expected workload, the actual workload, and the desired workload. For most tenure-track faculty, unless they are hired specifically to support research, up to 60 percent of their total load is dedicated to teaching. At issue is the perception that since Boise State University is working toward designation as a research university (it is still considered "master's large" in the current iteration of Carnegie rankings), there is a growing culture that emphasizes research more highly than teaching. All interviewees felt that Boise State University must maintain teaching as its central focus. Furthermore, each in his or her own way pointed to the fact that workload was something that can be, and is, adjusted based on faculty strengths and needs. Such adjustments are taken into consideration in the P\&T process.

On the whole, administrators interviewed about P\&T policy or other tangentially related policies, did not point to any areas that they felt would inhibit a faculty member from exploring innovative teaching methods in her or his engineering courses. In their estimation, further policies that institutionalize pursuit of innovation to any degree would not be sustainable and would likely have little impact on effectiveness. They felt that both college and university support structures are adequate to scaffold any who wish to explore new pedagogies, and that such attempts would be well-received as long as faculty members do their part in reflecting on the rationale for change and its outcomes. 


\section{Conclusions}

This paper presented preliminary results from data collected using a 360-degree approach and provided three new perspectives: that of students, published documents, and administrators. These perspectives are part of a larger 360-degree approach for data collection that also includes the perspectives of self and colleagues. This 360-degree approach provides a foundation for bridging the gap, often referred to as the 'valley of death,' between engineering education research and the common practice of engineering education.

The student data collected confirm the reliability and validity of the faculty self-report data. The published documents and interviews with administrators provide the work environment of the faculty. Next, this work environment reality must be compared with the faculty perceptions of it to examine where they differ, as well as how those perceptions may influence an individual's knowledge of engineering education innovations and his or her willingness to adopt new innovations.

\section{Acknowledgements}

This material is based upon work supported by the National Science Foundation under Grant No. EEC-1037729. Any opinions, findings, and conclusions or recommendations expressed in this material are those of the authors and do not necessarily reflect the views of the National Science Foundation.

\section{Appendix: Questions for Administrators}

1 A number of BSU policy documents related to evaluation of faculty members, to include promotion and tenure and workload policies, use the phrase, "teaching effectiveness" or similar terms. In your estimation, what constitutes "teaching effectiveness?"

2 One way that "teaching effectiveness" has been and continues to be measured is via student evaluations. Can you speak to the strengths and weaknesses of student evaluations in general? [in fact, in the COEN Volume 1 binder, this is all that is required for evidence of teaching effectiveness].

3 The Student Evaluation Policy (\#4300) states that the evaluations "...are designed primarily to assist individual instructors in improving their teaching performance." In your experience, how are the evaluations used in any systematic way by different departments within COEN to help improve teaching?

4 Do any departments within COEN use external evaluators to judge the quality of teaching?

5 In both the Faculty Promotion Guidelines and in the Faculty Tenure Guidelines, as well as in the College of Engineering Promotion and Tenure Policy, the following phrase, "innovations in teaching" is used. What, in your estimation, qualifies as "innovation" in teaching?

a. How are teaching innovations best measured? 
b. How do the current policies in COEN impact innovative teaching practices at BSU?

6 How do the current policies at BSU impact innovative teaching practices in engineering?

a. How much do you see faculty in COEN taking advantage of the CTL's professional development ("10 for Tenure") program?

b. Virginia Tech has had a program for at least the past number of years called the "Faculty Development Institute," where every three (maybe four) years, faculty can earn a new computer after they participate in 12 hours (or so) of technology or pedagogical training. Would you foresee this ever happening at BSU?

7 Should professors at BSU wish to hone their teaching skills, what affordances and incentives are in place for them to do so?

a. How much do you see faculty taking advantage of the CTL's professional development related to teaching?

8 In your opinion, which incentives are the most effective in motivating a faculty member to improve his or her teaching?

a. What do you believe are the barriers that prevent more faculty from becoming innovative?

9 How do we sustain the culture of a teaching university while at the same time grow toward the "metropolitan research university of distinction?"

10 Is there any type of mentorship or modeling for new faculty as to the expectations for the classroom within COEN? If there is not, should there be? If one were to be established, what do you think it should look like?

11 At annual review of faculty, are any student artifacts aligned with standards? [See I.B.1.a. \& b. as related to teaching].

12 The weighting of teaching-research-service is thought to be equal in the promotion \& tenure decision process. Based on BSU policy (either university or college), can you speak to the accuracy (or not) of this perception?

13 Faculty sometimes feel that if they try to be innovative, they will get "dinged" on student evaluations. Anecdote from the tenured professor at ASEE (tenured) who said he simply disliked low evaluations and thus tended to resort to lecture rather than do new things. What kind of policies are in place to help protect a faculty member who wants to be innovative, but whose attempts may not be well-received by students?

14 There seems to be a bit of a disconnect in policy documents. On one hand, faculty are told that all three aspects of their dossier must be "effective" or "outstanding."

However, the COEN faculty promotion guidelines, it states (referring to \#4560, the workload policy), "It is not anticipated or desired that all faculty will make equal contributions in all three areas and a desirable diversity in contribution is encouraged." With such a perspective, the message seems to be that teaching is not necessarily held in high regard, as long as one is doing outstanding work in other areas. How would you react to this assertion?

15 ABET Accreditation, I.B.2., states, "Promote quality and innovation in education." What does BSU's COEN do to show evidence of this? 


\section{References}

1. Ford, G.S., T.M. Koutsky, and L.J. Spiwak. (2007). "A Valley of Death in the Innovation Sequence: An Economic Investigation." Phoenix Center for Advanced Legal and Economic Public Policy Studies.

2. Fincher, S.A. (2009). "Useful Sharing." Journal of Engineering Education, 98(2), 109-110.

3. Watson, K. (2009). "Change in Engineering Education: Where Does Research Fit?" Journal of Engineering Education, 98(1), 3-4.

4. Jamieson, L.H. and J.R. Lohmann. (2009). "Creating a Culture for Scholarly and Systematic Innovation in Engineering Education: Ensuring U.S. engineering has the right people with the right talent for a global society." ASEE.

5. Loui, M.C. (2007). "Moments of Inertia: Toward an Agenda for Sociological Research on Why Engineering Professors Resist Changes in Pedogogy and Curriculum." The Acceptance and Diffusion of Innovation: A Cross-Curricular Perspective on Instructional and Curricular Change in Engineering, R. Spalter-Roth, N. Fortenberry, and B. Lovitts, eds., American Sociological Association, Washington, DC.

6. Fox, M.F. (2007). "Institutional Transformation in Academic Science and Engineering: What is at Issue." The Acceptance and Diffusion of Innovation: A Cross-Curricular Perspective on Instructional and Curricular Change in Engineering, R. Spalter-Roth, N. Fortenberry, and B. Lovitts, eds., American Sociological Association, Washington, DC.

7. Croissant, J. (2007). "Organizational Contexts and Faculty Behavior: Frameworks for Research on the Social Dynamics of Campus Change." The Acceptance and Diffusion of Innovation: A Cross-Curricular Perspective on Instructional and Curricular Change in Engineering, R. Spalter-Roth, N. Fortenberry, and B. Lovitts, eds., American Sociological Association, Washington, DC.

8. Spalter-Roth, R., N. Fortenberry, and B. Lovitts. (2007). "The Acceptance and Diffusion of Innovation: A Cross-Curricular Perspective on Instructional and Curricular Change in Engineering." American Sociological Association, Washington, DC.

9. Bowen, D.M. (2007). "Engineering Education Innovations: Modeling the Influence of Organizational Context and Faculty Behavior." The Acceptance and Diffusion of Innovation: A Cross-Curricular Perspective on Instructional and Curricular Change in Engineering, R. Spalter-Roth, N. Fortenberry, and B. Lovitts, eds., American Sociological Association, Washington, DC.

10. Ambrose, S. (2007). "Exploring the Role of the Reward System in the Diffusion of Innovation in Engineering Education." The Acceptance and Diffusion of Innovation: A Cross-Curricular Perspective on Instructional and Curricular Change in Engineering, R. Spalter-Roth, N. Fortenberry, and B. Lovitts, eds., American Sociological Association, Washington, DC.

11. Kramer, L. (2007). "Greedy Institutions and Faculty Involvement in Retention." The Acceptance and Diffusion of Innovation: A Cross-Curricular Perspective on Instructional and Curricular Change in Engineering, R. Spalter-Roth, N. Fortenberry, and B. Lovitts, eds., American Sociological Association, Washington, DC, 113119.

12. Davis, K.A., S.M. Miller, and R. Perkins. (2011). "Bridging the Valley of Death: A $360^{\circ}$ Approach to Understanding Adoption of Innovations in Engineering Education." 2011 ASEE Annual Conference \& Exposition, Vancouver, BC, Canada.

13. Nowack, K.M. (1999). "360-Degree Feedback." Intervention Resource Guide: 50 Performance Improvement Tools, D.G. Langdon, K.S. Whiteside, and M.M. McKenna, eds., Pfeiffer, San Francisco, CA.

14. Miller, S.M., K.A. Davis, and R. Perkins. (2012). "Bridging the Valley of Death: A Preliminary Look at Faculty Views on Adoption of Innovations in Engineering Education." 2012 ASEE Annual Conference \& Exposition, San Antonio, TX, USA.

15. Luft, J. and H. Ingham. (1955). "The Johari window, a graphic model of interpersonal awareness." Proceedings of the western training laboratory in group development Los Angeles, CA, UCLA.

16. Boise State University (2006). Work Load for Tenured and Tenure-Track Faculty, BSU \#4560, http://policy.boisestate.edu/wp-content/uploads/2011/05/4560_WorkloadForTenuredFaculty 03222011.pdf

17. Boise State University (1999). Student Evaluation of Faculty, BSU \#4300, http://policy.boisestate.edu/wpcontent/uploads/2011/05/4300_StudentEvaluationofFaculty.pdf

18. Boise State University (2009). Annual Faculty Performance Evaluation, BSU \#4290, http://policy.boisestate.edu/wpcontent/uploads/2011/05/4290_AnnualFacultyPerformanceEvaluation_03182011.pdf 
19. Boise State University (2010). Faculty Evaluation Procedures, COEN FAC 002, http://coen.boisestate.edu/wpcontent/uploads/2012/09/FAC-002-Faculty-Evaluation-Procedures-FINAL-APPROVED-052110.pdf

20. Boise State University (2008). Faculty Promotion Guidelines, BSU \#4340, http://policy.boisestate.edu/wpcontent/uploads/2011/05/4340_FacultyPromotionGuidelines 03182011.pdf

21. Boise State University (2010). Promotion and Tenure Policy and Procedure, COEN FAC 001, http://coen.boisestate.edu/wp-content/uploads/2012/09/FAC-001-Promotion-and-Tenure-Policy-and-ProcedureFINAL-APPROVED-052110.pdf

22. Borrego, M., J.E. Froyd, and T.S. Hall. (2012). "Diffusion of engineering education innovations: A Survey of awareness and adoption rates in U.S. engineering departments." Journal of Engineering Education, 99(3), 185207. $<$ http://jee.org/2010/july/2.pdfs

23. Lane, J.L. (2001). "Teaching and learning innovations in higher education: Faculty perceptions of sustainability," Doctoral dissertation, The Pennsylvania State University.

$<$ https://etda.libraries.psu.edu/paper/5889/1156>

24. Lattuca, L.R. (2011). "Influences on engineering faculty members' decisions about educational innovations: A systems view of curricular and instructional change [Online white paper]." Center for the Study of Higher Education, The Pennsylvania State University. $<$ http://www.nae.edu/File.aspx?id=36674>

25. Nor, N.M., N. Rajab, and K.M. Ismail. (2008). "Educating the engineer of 2020: Malaysian scenario." International Conference on Engineering Education, Budapest, Hungary. $<$ http://www.ineer.org/Events/ICEE2008/full_papers/full_paper291.pdfs $>$

26. Brewer, D.J. and W.G. Tierney. (2010). "Barriers to innovation in U.S. higher education." American Enterprise Institute conference, "Reinventing the American University: The Promise of Innovation in Higher Education," Washington, DC.

$<$ http://www.aei.org/files/2010/06/03/Dominic\%20Brewer\%20and\%20William\%20Tierney\%20\%20Barriers\%20to\%20Innovation\%20in\%20U.S.\%20Higher\%20Education.pdf $>$

27. Boise State University (2009). Faculty Tenure Procedures, BSU \#4370, http://policy.boisestate.edu/wpcontent/uploads/2011/05/4370_FacultyTenureProcedures_03222011.pdf 